\title{
WHAT DO GREEKS BELIEVE ABOUT ELDERS AND MENTAL CAPACITY?
}

\section{Giannouli}

\section{Vaitsa Giannouli}

School of Medicine, Aristotle University of Thessaloniki, Greece

*Correspondence: School of Medicine, Aristotle University of Thessaloniki, Thessaloniki 54124

Email: giannouliv@ hotmail.com

\begin{abstract}
Despite the plethora of studies abroad, in Greece views on individuals with intellectual disabilities and older persons with mental health problems is not a well investigated topic. The results of the present study reveal that generally acts with financiallegal implications (mainly financial decision-making capacity) are of concern to the participants, as they consider this sort of capacity the main predictor for legal (in)capacity on the whole, especially when they consider elderly patients. Participants have doubts about the appropriateness of the current assessment methods followed by forensic psychiatrists and psychologists in Greece and hope for future improvements in the field of legal capacity assessment. In addition to that participants seem to welcome any form of provided information (live lectures from conferences, videos, interviews, discussion forums and texts) from experts with an emphasis on issues for elders. No significant differences were found in the expressed views based on gender or age, but subtle differences were found according to educational level.
\end{abstract}

Keywords: attitudes, mental capacity, law, elders, Greece.

\section{Introduction}

In health care there is an ever growing interest in elderly patients suffering neurological or psychiatric disorders ${ }^{1}$. However, legal issues concerning not only the clinical, but also the legal, aspects of these patients are not adequately represented in everyday discourse. More specifically, the evaluation of mental or decision-making capacity regarding medical and legal issues still remains a hard problem to solve and therefore seems to be neglected. Children, adults and elders, patients or not, must have the capacity to receive, comprehend and utilize the information with which they have been provided, not only in dealing with everyday problems, but also in clinical and legal settings ${ }^{2}$. Legal capacity is a person's capability and power under law to engage in a particular undertaking or transaction or to maintain a particular status or relationship with another person and for this reason it constitutes a critical intersection of law and clinical practice ${ }^{3}$. Legal capacity is linked and interchangeably used with the term civil capacity. Civil capacity assessment can take many

\footnotetext{
${ }^{1}$ Capisizu A, Aurelian SM, Bogdan C. Medical and legal aspects of elderly patients with dementia. Romanian Journal of Legal Medicine. 2014; 22: 51-54.

${ }^{2}$ Tepper AM, Elwork A. Competence to consent to treatment as a psycholegal construct. Law and Human Behavior. 1984; 8: 205-223.

3 Alzheimer Europe. Greece: Legal capacity and proxy decision making. 2010. Chapter accessed online on 10 April 2014 http://www.alzheimer-europe.org/Policy-inPractice2/Country-comparisons/Legal-capacity-and-proxy-decision-making/Greece
} 
forms, such as assessment of specific capacities concerning medical consent, capacity for sexual consent, financial capacity, testamentary capacity, driving capacity and capacity for independent living ${ }^{4,5}{ }^{6}$. All these terms have at their base the decision-making capacity of individuals, which requires multiple cognitive functions (such as memory, executive skills etc. $)^{6}$. Of course, in Greece there is an unsatisfactory definition and vague explanation by the Greek Civil Code (articles 127-152), which states that generally, minors, individuals with mental disorders and individuals under the influence of drugs or alcohol have no right to enter into any legal contracts ${ }^{7}$. The above create a series of theoretical questions in ethics and, more practically, in situations of guardianship in legal courts, which require a legal determination regarding loss or conservation of competency for individuals.

The aim of the present study is to investigate further the views that contemporary Greeks have on issues concerning law, medicine and psychology, and to record, for the first time, their opinions about clinical-legal capacity generally for patients with neurologic and/or psychiatric diseases and, more specifically, for elders with a diagnosed mental disorder, and to determine what kind(s) of information the Greek public is seeking and in what form.

\section{Method}

During 2014, a total of two hundred fifty-three healthy participants (96 men and 157 women, with ages ranging from 18-80 years) from different geographical areas throughout Greece, took part in a public opinion survey on mental capacity. Participants were categorized by age into young adults (ages 18-35 years; $n=89$ ), middle-aged adults (ages 36-55 years, $n=104$ ), and older adults (aged older than 55 years, $n=60$ ). In addition, they were categorized according to their educational level and their current occupation as 120 students (30 medical students, 28 law students, 32 psychology students, and 30 students from other non-relevant specialties), 101 professionals (35 medical doctors, 37 legal professionals -26 lawyers and 11 notaries- and 29 psychologists, and 32 laypeople with occupations ranging from workers to professors). Nearly half of the participants were relatives of living elders who were healthy or patients with a memory problem ( 79 male, 175 female). Of these, $60 \%$ were adult children companions of elder patients, $30 \%$ were wives or husbands and $10 \%$ were assistants. Nearly all of them had a frequent communication (at least once a week) with elderly patients. Geographically, 54\% were citizens of Thessaloniki, and the remainder were living in rural nearby areas (46\%). In order to collect the information, a 20 closedand-open type questionnaire was used, which the participants completed by themselves. So, the participants completed a brief 5-point Likert scale questionnaire (consisting of statements from strongly disagree to strongly agree, which was previously used in another study ${ }^{8}$ about general capacity assessment issues regarding different groups of mental health patients (e.g.

${ }^{4}$ American Psychological Association. Assessment of older adults with diminished capacity. A handbook for lawyers. American Bar Association Commission on Law and AgingAmerican Psychological Association; 2005.

${ }^{5}$ American Psychological Association. Assessment of older adults with diminished capacity. A handbook for psychologists. American Bar Association Commission on Law and AgingAmerican Psychological Association; 2006.

${ }^{6}$ Demakis GJ. Civil capacities in clinical neuropsychology: Research findings and practical applications. New York: Oxford University Press; 2011.

${ }^{7}$ Greek Civil Code. Athens: Athens Bar Association Publications; 2012.

${ }^{8}$ Giannouli V, Vlaikidis N, Koutsouradis A, Tsolaki M. Views on contractual capacity for patients with neurological disorders. In: Vlaikidis D. Proceedings of the $1^{\text {st }}$ Conference "Recent Developments in Neurology and Related Fields"; 2013 Oct 10-12; Greece, Thessaloniki; p. 29. 


\section{Giannouli}

patients suffering from schizophrenia, bipolar disorder, dementia patients etc.) and on more concrete capacity issues concerning elderly people and more specifically the elderly person they accompanied or with whom they lived with. In addition to that, they were asked about what kind of information they need, how they would like to receive that information and by what means - in which form. There was also a brief semi-structured interview with each of the participants regarding clarifications on their personal answers.

\section{Results}

The participants revealed an interest (agree and strongly agree statements) primarily in what is going on in Greece (97\%), in what is going on in the European Union (76\%), and in what is going on internationally/abroad (63\%). The group for which they believe that they need the most information is the elderly demented patients $(88 \%)$ and secondarily the group of adult patients with psychiatric disorders (e.g., schizophrenia) (43\%). Concerning the question of what kind of legal issue they consider to be the most important, the vast majority indicated that they believe that financial decision-making capacity issues in the form of sales, purchases, loans, leases, donations and testaments are in the heart of contemporary law problems in Greek courts generally for 'incapacitated adults' (87\%) and more specifically for elderly patients suffering neurocognitive disorders (90\%), and they believe that this form of capacity is the best predictor for legal (in)capacity on the whole (72\%). Of course, the group of non-expert participants (that is those who did not have a formal education in medicine, law or psychology) could not indicate the way(s) or relevant questions to be answered by experts for the clarification of this issue (94\%), but all of the participants (experts and non-experts) indicated doubts about the appropriateness of the current mental capacity assessment methods followed by forensic psychiatrists and psychologists not only in Greece, but also worldwide (93\%) and expressed hope for future improvements in the field (98\%). Other topics that occurred (with the exception of autonomy versus guardianship issues-legal protective measures for general decision-making capacity $(95 \%)$ and more specifically financial capacity (90\%)) were about elder abuse and human rights law (85\%), involuntary hospitalization (79\%), medical malpractice (74\%), and disclosure of private information with an emphasis on the diagnosis and information retained as medical health records (64\%). No significant differences were found for the above themes in the views of men and women ( $>.05)$, younger and older participants ( $\mathrm{p}>.05$ ), more and less educated participants (university graduates, lawyers, doctors versus high school and primary school graduates) ( $>$ >.05) and participants living in urban or rural areas $(\mathrm{p}>.05)$ for all of the above questions following $\mathrm{T}$ tests and one-way ANOVAs, which are in line with previous findings coming from a much smaller sample [9]. Furthermore, when the same participants were asked if they wish to get more information on these issues they uniformly replied in a positive way ( 5 out of 5 on the Likert scale), without showing a statistically significant difference in their preference about the provider of these information (whether it is the state or a private institution).

When asked to indicate the ways that they would prefer to get informed on the above legal, medical and psychological issues for the elders, they responded, regardless of their demographic characteristics, that they would need online information (88\%), although when asked if they find the internet as an easy way to get informed, only $74 \%$ responded in a positive way. Mainly negative answers were given by the group of middle-aged and older participants with a low educational level (basic primary education). The majority of the participants did not show preference for a specific form of open access information, but they uniformly proposed that a future online platform could contain videos from lectures coming from conferences or TV shows, interviews with experts, discussion forums and texts written by the experts themselves. A differentiation was found only among the groups of health and law professionals. Doctors expressed a strong desire, in the given open questions, to get more information primarily on the basic principles of civil and secondarily on penal legislation. 
Doctors main question was how the law protects an individual when she/he cannot make decisions for herself or himself.

On the other hand, lawyers and notaries focused less on the legislative framework and more on the basics concerning the clinical picture of the patients, the symptomology and the ways of determining or noticing mental disorders in the elderly. As a second point, both groups expressed the desire to get more detailed information on the intersection of the two fields as well as on the state-of-the-art in their own field. Laypeople did not show a specific similar pattern in their preferences but indicated they lack completely official or unofficial information on these issues. Finally, when asked if they would prefer to get informed and at the same time retain their anonymity, $89 \%$ responded in a positive way, which means that a future initiative should take care not to display personal data of visitors and (if in an electronic form) should not demand a login function.

\section{Conclusions}

In conclusion, these results of rounded percentages suggest that today Greek citizens show a uniformly negative overemphasis solely on specific acts which have both legal and financial implications. Greeks believe that elder law is an insufficiently researched area, and their primary concern is with estate planning and administration, health-care issues (patients' rights about informed consent treatment decisions and end-of-life decisions) and general guardianship decisions. The findings indicate that a large percentage of Greek people who are concerned with the financial decision-making capacity of elder patients for financialcontractual issues, along with the finding that elder patients (even those with Mild Cognitive Impairment) face serious difficulties in the above mentioned fields ${ }^{9}$, may demonstrate more fully the necessity of applying legal initiatives similar to the Mental Capacity Act 2005, which is an Act of the Parliament of the United Kingdom with the primary purpose to provide a legal framework for acting and making decisions on behalf of adults who lack the capacity to make particular decisions for themselves ${ }^{10}$.

The staggering finding of the present research is that the Greek society, as a whole today, is composed of a majority of individuals who tend to focus on contract law, and more specifically on diminished decision-making capacity for finances. This restriction of general interest to ethical questions with legal/financial implications may lead future research to focus on how public opinion changes might occur over time on the issue of property possession and control for patients with mental illness and on the clarification of the possible cultural factors that may shape public opinion across different ethnic groups on possible medical or legal malpractice concerning elderly patients. Of course, the Greek public demonstrated a remarkable thirst for a wide range of information, and due to the lack of available relevant resources, it seems that they desperately want to initiate a continued dialogue on elders' medical-psychological issues and civil-penal law, by bridging the gap between the experts from different scientific fields. Mental capacity of the elderly is a challenging field where medical and (neuro)psychological knowledge meet with legal problems and legal proceedings. Mental capacity of the elderly, not only in Greece, but also in the European Union, seems not only to be a matter of private confusion, but also, a matter for which, public policy and NGOs could, and should, unite their actions to evaluate critically the empirical evidence and incorporate it into the future legislative changes. At the same time policy and NGO leaders must commit themselves to promoting education on related disciplines (medical-psychological-legal) for the group of persons with intellectual impairment.

\footnotetext{
${ }^{9}$ Giannouli V, Tsolaki M. Legal capacity of the elderly in Greece. Hellenic Journal of Nuclear Medicine. 2014; 17: 2-6.

${ }^{10}$ Mental Capacity Act. Code of Practice. London: TSO; 2005.
} 


\section{Giannouli}

\section{Acknowledgements}

I would like to thank the Angelopoulos Fellowship Program, Professor Joan Williamson for the English language editing, and Mrs Holly Taylor Sargent for her valuable help as my Commitment Mentor at Clinton Global Initiative University 2014.

\section{Bibliography}

1. Capisizu A, Aurelian SM, Bogdan C. Medical and legal aspects of elderly patients with dementia. Romanian Journal of Legal Medicine. 2014; 22: 51-54.

2. Tepper AM, Elwork A. Competence to consent to treatment as a psycholegal construct. Law and Human Behavior. 1984; 8: 205-223.

3. Alzheimer Europe. Greece: Legal capacity and proxy decision making. 2010. Chapter accessed online on 10 April 2014 http://www.alzheimer-europe.org/Policy-inPractice2/Country-comparisons/Legal-capacity-and-proxy-decision-making/Greece

4. American Psychological Association. Assessment of older adults with diminished capacity. A handbook for lawyers. American Bar Association Commission on Law and Aging-American Psychological Association; 2005.

5. American Psychological Association. Assessment of older adults with diminished capacity. A handbook for psychologists. American Bar Association Commission on Law and Aging-American Psychological Association; 2006.

6. Demakis GJ. Civil capacities in clinical neuropsychology: Research findings and practical applications. New York: Oxford University Press; 2011.

7. Greek Civil Code. Athens: Athens Bar Association Publications; 2012.

8. Giannouli V, Vlaikidis N, Koutsouradis A, Tsolaki M. Views on contractual capacity for patients with neurological disorders. In: Vlaikidis D. Proceedings of the $1^{\text {st }}$ Conference "Recent Developments in Neurology and Related Fields"; 2013 Oct 10-12; Greece, Thessaloniki; p. 29.

9. Giannouli V, Tsolaki M. Legal capacity of the elderly in Greece. Hellenic Journal of Nuclear Medicine. 2014; 17: 2-6.

10. Mental Capacity Act. Code of Practice. London: TSO; 2005. 